\title{
"IF YOU CAN'T SEE IT, YOU CAN'T BE IT" - OUTREACH CHALLENGES IN PREPARING THE YOUNG GENERATION FOR A CAREER IN THE SPACE INDUSTRY
}

\author{
Remco Timmermans ${ }^{\mathrm{a} *}$, Daniela Rodríguez-Martínez ${ }^{\mathrm{b}}$, Emma Holling , Oniosun Temidayo Isaiah $^{\mathrm{d}}$. \\ ${ }^{a}$ International Space University (ISU), United Kingdom, remco.timmermans@.community.isunet.edu \\ ${ }^{\mathrm{b}}$ Universidad Panamericana, School of Communications, Mexico City, Mexico, danyrm.media@gmail.com \\ ${ }^{c}$ The Holt School, Holt Lane, Wokingham, United Kingdom, emma@aerospace4all.com \\ d Federal University of Technology Akure, Ondo state, Nigeria, temidavo.isaiah@spacegeneration.org \\ * Corresponding Author
}

\begin{abstract}
This paper is the result of an international, intercultural and interdisciplinary study on the outreach challenges of preparing students between the ages of 15 and 25 years for a career in the space industry. This qualitative study aimed to find and compile the best outreach practices and recommendations for engaging young people in an increasingly diverse world.

Traditionally, space outreach has been biased and limited to a small number of careers in leading nations in the space industry. With the industry undergoing huge changes, new space actors are emerging even in nations that lack a national space program. Thus a new challenge for outreach professionals is to paint a realistic and updated picture of the paths towards a career in space in this new industry for their young audience. Not only have opportunities for space outreach grown in new geographies, with their own cultural and lingual characteristics, but also in traditional space nations, which are driving towards a more inclusive and diverse communication to their audiences.

This paper is built around a literature study into outreach for diversity in the space industry, plus a survey among space outreach practitioners around the world. The analysis of this survey, in the context of literature findings, leads to new insights into outreach practices for new space audiences, the challenges involved in engaging these new audiences, and in providing them with an objective perspective of career opportunities in the local and international space sector. The analysis includes topics like the diversity of role models and the advantages of using varied channels to reach young audiences. The paper concludes with a set of practical recommendations for space outreach professionals and researchers.
\end{abstract}

Keywords: public outreach, space career, diversity, role models, case study, education

\section{Acronyms/Abbreviations}

Science, technology, engineering, and maths (STEM)

Question 1 (Q1)

European Union (EU)

United Kingdom (UK)

United States (US)

International Astronautical Federation (IAF)

Education and Public Outreach (EPO)

Organisation for Economic Co-operation and Development (OECD)

United Nations Office for Outer Space Affairs (UNOOSA)

\section{Introduction}

In September 2021, the world witnessed the launch and mission of the 'first all-civilian mission to orbit': the Inspiration4. In this mission, four civilians orbited Earth on a SpaceX Crew Dragon capsule for three days. The name 'Inspiration4' refers to the crew of four civilians, introducing a new era for human spaceflight and exploration, inspiring the world about the fact that space is now accessible to all [1]. This "accessibility" is highlighted by the diversity of the crew, all representing different parts of society, including a cancer survivor and prosthetic leg bearer. Although it tries to answer many questions, the mission really raises many more questions about the real inspiration and real accessibility of space to 'anyone' at this point in history.

Inspiration 4 comes only a few weeks after two other new human spaceflight milestones: the first 'passenger' flight of Virgin Galactic's SpaceShip Two [21] and Blue Origin's New Shepard [22], carrying two billionaire-led crews of paying and non-paying passengers on a suborbital ride into space. In October 2021, Blue Origin is planning to take another group of four people on a similar ride [23]. These missions really mark the start of more frequent short ballistic trips to high altitudes, carrying paying private passengers on the trip of a lifetime. 
To date, these new missions have provided several space flight firsts: from the oldest and youngest travelers to space, to the richest. Not all, but most of these new space travelers carried a US passport, where all others came from a small number of European countries, including the UK and the Netherlands.

The question this paper would like to raise therefore is about the diversity of role models. As the world is watching these new 'accessible' space missions featuring 'normal civilians': Are we really seeing a more diverse community of space role models, or is there still room for improvement?

This paper also researches the presumption that role models are important for the future development of a truly global, truly equal, and diverse space sector, offering equal opportunities to anyone aspiring to be part of the space sector, be it in space or on the ground, supporting space exploitation and exploration. The hypothesis here is that these opportunities are still far from equal around the world and around different communities in today's society.

\section{Methodology}

In order to obtain insights regarding the current international status and characteristics of space outreach, this qualitative study used the methodology of creating a theoretical framework through a literature review, followed by a targeted survey among space outreach practitioners.

\subsection{Literature review}

The theoretical framework for this paper was developed in a literature review and a scan of the current state of diversity, role models, mentoring, and the role of outreach in the global space industry. This review identified a clear imbalance in diversity, missing role models, but also initiatives to improve this imbalance.

\subsection{Survey}

In order to obtain direct perspectives from the people who do space outreach around the globe, a total of 30 communicators were consulted for this survey. The criteria for selecting them was according to the country where they are currently performing outreach: the total of 16 questions was sent to 10 contacts living in America, Europe, Africa, Asia, and Oceania, respectively, from July 1st to September 1st, 2021. In the end, only 30 responses were received from colleagues in America, Europe, and Asia. Additionally, a female-male equitable distribution was achieved in the answers, with the participation of 15 women and 15 $m^{1}$, as well as different generations, were involved: being 18 years old the youngest communicator, and 59 years the oldest.

The purpose of this survey is to know and listen to the diversity of opinions that communicators have about their country's space outreach activities, the outreach methods currently used, the age of their target audience, the visibility of STEM and non-STEM careers, the perception about the influence of space outreach in students, and the diversity and inclusivity reflected in space outreach.

The answers were analysed according to the question type (nine quantitative and seven qualitative) and results are presented in section 4 . The complete questionnaire can be found in Appendix A.

\section{Literature review}

\subsection{The space workforce around the world}

\subsubsection{Size of the global space industry}

According to a recent OECD study [2] "The global space sector employed around 1 million persons around the world in 2017. To give orders of magnitude, around 350,000 full-time employees are active in the United States, 200,000 in the Russian Federation, and around 60,000 in Europe. These are only estimates, as detailed official statistics are not available for every country."

This space-related employment includes all positions in government, research, space manufacturing, its suppliers, space operators, and the wider space services sector, like satellite data companies. It does not include military space and universities.

\subsubsection{Geographical distribution of the space industry}

The space industry was long dominated by only a few large governments, but since the end of the space race, the list of space-faring nations has grown significantly. According to Space Policy Online, "almost every country in the world is a "spacefaring" country in the sense that they use satellites for communications and weather forecasting, and increasingly for satellite navigation and resource management. A smaller number of countries, along with companies and international organizations, own satellites"[6].

The level at which different countries are active in space differs a lot. Only Wikipedia seems to provide an up-to-date overview of the countries around the world

${ }^{1}$ Surveyed people indicated that they recognized themselves as a woman or a man, respectively, as it was given the opportunity to indicate freely what gender they identified as. 
that have some sort of spaceflight capability, as shown in Figure 1 [7]

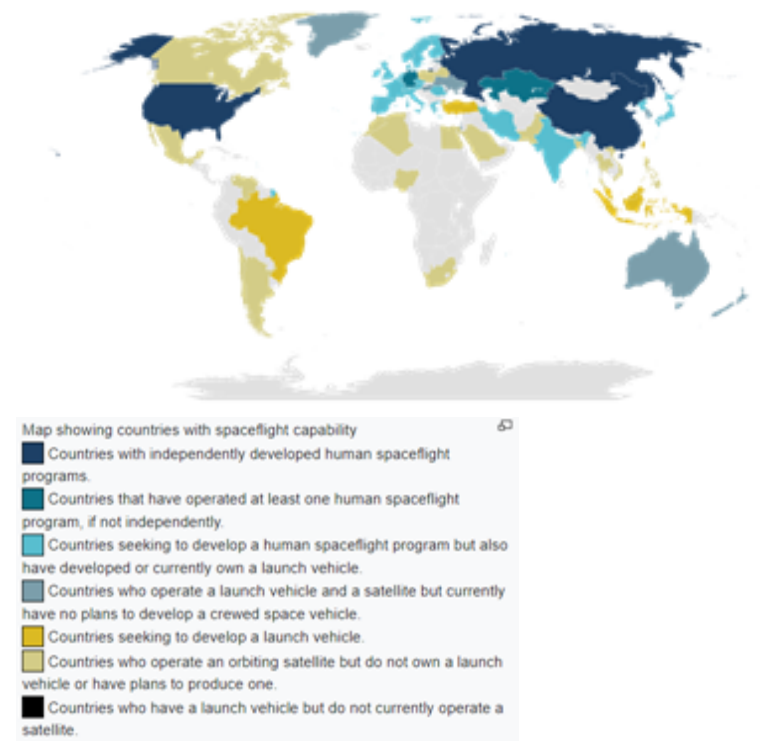

Figure 1. Map showing countries with spaceflight capability.

In this map, the distribution of spaceflight capability is not equally distributed over the countries of the world. The emphasis clearly lies in the western world, including North America, Europe, and most of Asia. There are still large clusters of countries not or barely involved in space, including most of Africa and Latin America. This unequal distribution has an impact on space outreach and the perception of space as a feasible industry for education and careers.

\subsection{Diversity in the space industry}

The Oxford dictionary defines diversity as "The fact, condition, or practice of including or involving people from a range of different social and ethnic backgrounds, and (more recently) of different genders, sexual orientations, etc" [3].

Even though diversity may be easily understood as a concept, measuring true diversity in an organization, an industry, or in society as a whole is not as straightforward as it sounds. Most literature on the topic recognizes three dimensions of diversity:

- Variety - describes the number of different types, species or categories presented. The variety is bounded by the total number of types in the classification or taxonomy that is used [4].

- Balance - describes how individuals or elements are distributed across these types. When elements are concentrated in few types the balance is low, while a high balance indicates a more even distribution [4].
- Disparity - takes into account to what extent the types considered differ from each other in terms of some given features or characteristics. If the types considered are very similar, they have low disparity[4].

An increase along any of these three dimensions corresponds to an increase in overall diversity. A proper measure of diversity should therefore take into account all three dimensions.

\subsubsection{The case for diversity}

It is widely accepted that more diverse organizations perform better than less diverse peers. The growth of Silicon Valley is addressed by some to its great variety in people's backgrounds. In its report "Diversity wins: How inclusion matters" [5], the McKinsey company analyzed 1,000 large companies from 15 countries, across different sectors in 2019: "Our latest analysis reaffirms the strong business case for both gender diversity and ethnic and cultural diversity in corporate leadership - and shows that this business case continues to strengthen. The most diverse companies are now more likely than ever to outperform non-diverse companies on profitability"

"Our 2019 analysis finds that companies in the top quartile of gender diversity on executive teams were $25 \%$ more likely to experience above-average profitability than peer companies in the fourth quartile (...) Moreover, we found that the higher the representation, the higher the likelihood of outperformance. Companies with more than 30\% women on their executive teams are significantly more likely to outperform those between 10 and 30 percent women, and these companies in turn are more likely to outperform those with fewer or no women executives. As a result, there is a substantial performance differential-48\% - between the most and least gender-diverse companies".

The report doesn't look at just gender balance as a success factor but also considers other elements of a diverse workforce: "In the case of ethnic and cultural diversity, the findings are equally compelling. We found that companies in the top quartile outperformed those in the fourth by $36 \%$ in terms of profitability in 2019 , slightly up from $33 \%$ in 2017 and $35 \%$ in 2014 . And, as we have previously found, there continues to be a higher likelihood of outperformance difference with ethnicity than with gender.

\subsubsection{Diversity in the space industry}

In 2017, the OECD listed diversity recommendations in its space economy study, as "new challenges to overcome". "Further address human resources needs of the space sector, particularly in view 
of current digitalization trends that will increase competition for talent, and the still significant gender gap in space-related higher education and employment. Programs to promote fair participation in the space sector would benefit from thorough maps of gender employment, in order to track, evaluate and compare different initiatives" [2].

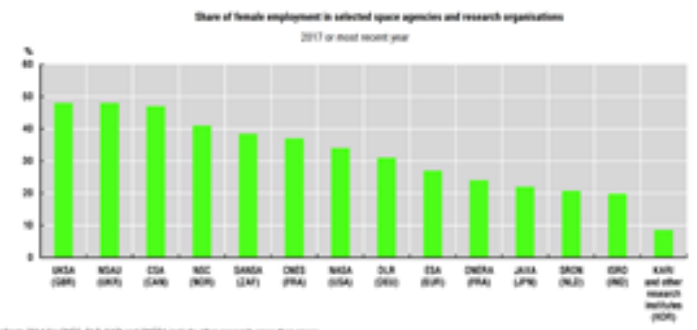

Figure 2. Share of female employment in selected space agencies and research organizations (OECD, 2017)

The table in Figure 2 clearly shows that none of the studied organizations reached a 50-50 balance in its male-female employment balance, with the UK, Ukrainian and Canadian space agencies being the best in class.

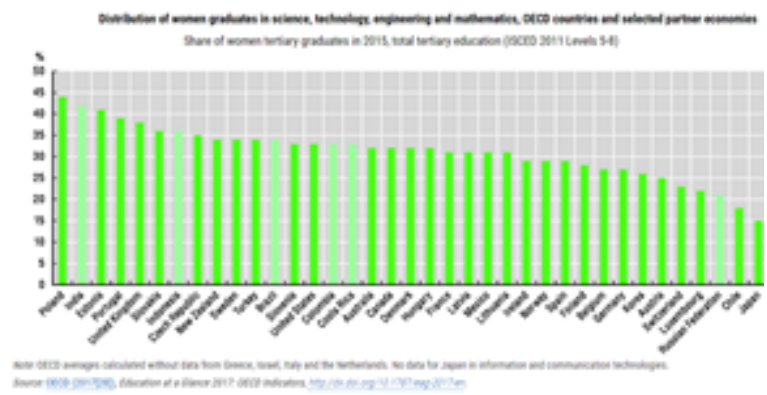

Figure 3. Distribution of women graduates in STEM studies (source: OECD)

Similarly, the table in figure 3 shows that participation in graduate-level education in STEM fields is not distributed equally in all OECD and selected partner economies, with the best in the class country showing a $44 \%$ female participation.

As you can see in the next section, for the IAF $3 \mathrm{G}$ diversity program gender is only one element of diversity. Although there is less scientific evidence than regarding gender balance, other elements of a culturally, socio-economically, generationally, geographically diverse space industry are likely similar, if not further out of balance.

\subsubsection{IAF $3 G+$ Diversity}

The International Astronautical Federation (IAF) distinguishes three elements of diversity, reflected in the name ' $3 \mathrm{G}$ ' for the program:

\section{- Geography \\ - Gender \\ - Generation}

Geographical diversity and global reach have been traditional features of the IAF since its creation. Attracting the young generation has been the focus of the IAF during recent. This has resulted in a significant increase in the number of young people engaged and participating in IAF activities. Gender diversity is still an area where strong progress needs to be achieved. Dedicated promotion of opportunities for female space actors within the Federation and the space sector in general, presenting successful role models, and encouraging the young generation of the female space community to aim for leadership positions shall help to reach a balanced and inclusive representation within the governance of the IAF, its Technical and Administrative Committees, as well as the IAC speakers' and authors' community.

The IAF has introduced the new IAF Vice President portfolio for Diversity Initiatives and New Space Economy and has initiated the "IAF Space Economic Platform - Bringing Space Down to Earth/Bringing Earth Up to Space", a complementary concept to the IAF " $3 G$ " initiative. Combining the two, the IAF has advanced its diversity initiative to " $3 \mathrm{G}+$ ", recognizing that the " $3 \mathrm{G}$ " elements are significant components of the new space economy [8].

\section{$\underline{3.3 \text { Role models }}$}

\subsubsection{Role models versus mentors}

According to classic research by Shapiro, Haseltine \& Rowe [12], role models "are individuals whose behaviors, styles and attributes are emulated by others. Unlike mentors, who are always "close" in that they are personally known in an interactive relationship with the young individual, role models often are not acquainted with the role model user, nor do they give their permission to be used in this way. Hence, role models may be close or distant to the role model user."

\subsubsection{Why do role models work?}

Answering the question of how role modeling works requires some study of social learning theory. People observe the behavior of others in certain situations and see the outcomes of that behavior. They will then use this knowledge to shape their own behavior in similar situations, expecting similar outcomes [13].

Role models change over time. Early role models are usually parents, modeling standards and providing a foundation for the development of their young 
offspring. Later role models are sought from a wider arena, and eventually, as careers become more important, from the corporate, entrepreneurial, or professional worlds. Often role models are selected because of the way in which they have overcome particular barriers seen as relevant by the users [14].

That same study found career stage differences in the construction of role models, with early-stage respondents drawing positive inferences from models who were close to them, to establish their self-concept, whilst middle and late-stage interviewees drew on role models for guidance in refining and affirming their self-concept [14].

Lockwood and Kunda [15] reported that superstars are often selected as role models, when there is some relevance for the comparison, for example, race, gender, and personality, and grounds for belief that comparable success could be achieved. An important part of the value of role models is that they demonstrate the possibility of attainment for those similar to them. In this respect, they are symbols of possibility, offering inspiration, and removing uncertainty - the fact that role models have got there means that it is possible to do so [15].

\subsubsection{Role models in STEM}

The above paragraph shows that users will look for similarities in background and personality, in order to identify with this person and create the belief that the user can achieve similar career goals. This is true across all fields, including STEM (Science, Technology, Engineering, and Maths).

An interesting study about the effect of role models in STEM on students was done by Bucknell University in 2018. This study concludes: "The results seem to indicate that students are accepting of non-outlier individuals as role models when these individuals are relatable and possess the qualities they value in a role model. This suggests that it is possible to create larger and diverse pools of role models for underrepresented minorities in STEM who represent a wide range of examples of feasible paths to success. Such a pool could influence student positive self-efficacy and positive self-identity development and potentially increase intrinsic motivation to pursue and persist in STEM" [10].

Similarly, a study investigating the effects of a role model intervention on women's STEM outcomes was published by Tulane University in 2019: "According to the stereotype inoculation model, female STEM role models (i.e., competent ingroup members) can serve as "social vaccines" who inoculate women in STEM against pernicious stereotypes even if they do not alter the stereotypes themselves. Exposure to role models has been shown to act as a buffer to women's negative experiences in STEM because seeing a competent ingroup member signals to other group members that they too are capable of success (i.e., role models). Same-sex role models are capable of improving women's test performance. In addition to improved performance, exposure to same-sex role models can also bolster women's identification with STEM, sense of belonging, and intention to pursue STEM" [11].

For this paper, based on the above, we distinguish two key characteristics of an effective role model:

- Similarity with the user, based on a variety of personal and background characteristics

- Achievability of role model success, based on the problems overcome to achieve success

\subsubsection{Role models in the space industry}

In one of the previous paragraphs, it was mentioned that role models and mentors, although performing very similar roles, differ in the personal relationships that they (don't) have with the user. In the space industry, role models have existed ever since the first human activities in space. Many of the early astronauts became immediate heroes to large audiences, representing human capabilities to conquer this new frontier in space. Over the history of space, we have seen that these role models have not been very diverse. Often selected based on physical and psychological strength, these privileged pioneers were often young, white males, with a background as fighter pilots. This image of 'The Right Stuff' then dug itself into the common consciousness of much of society, showing little similarity and even less achievability for the large majority of young people.

The early Soviet space program did slightly better in that regard than the American (while no other space programs existed), by selecting a women cosmonaut (albeit just the one for over 20 years) and inviting non-Russian passport holders to join the Soviet space program through the Interkosmos project.

Diversity in the astronaut and cosmonaut corps, being the most visible part of the space industry for many years, was very poor, and until today, with around 600 people have been in space to date, this group does not at all represent the full diversity of humanity. Women comprise $11.5 \%$ of the space flier community [16], with 65 women against 501 men, as counted in 2020. Numbers for other minorities, based on nationality, ethnicity, educational background, or physical ability are even less balanced.

\subsubsection{Mentors in the space industry}

Women's access to space, not just as astronauts but as users and creators of space services like Earth 
observation and satellite telecommunications, is still far from equal. But there are signs of progress. One is the Space4Women program run by the United Nations Office of Outer Space Affairs (UNOOSA), [17] which aims to ensure "the benefits of space reach women and girls and that women and girls play an active and equal role in space science, technology, innovation, and exploration." As UNOOSA director Simonetta di Pippo has noted, $40 \%$ of the targets of the UN's sustainable development goals rely on the use of space science and technology [16].

Mentorship programs, like the one mentioned by UNOOSA, are specifically designed to create a more inclusive and diverse workforce at all levels in the space industry [17].

As we saw in one of the previous paragraphs, role models and mentors are very similar in nature, and can in fact be one and the same, with the difference that in mentoring there is a personal relationship between the role model and the mentee, with the mentor actively promoting similarities and the achievability of their own success [12].

Other examples of recent diversity-increasing mentoring programs in the space industry include:

- UNOOSA Space4Women [17]

- Space Generation Advisory Council (SGAC) Mentoring Program [18]

- IAF Launchpad Mentorship Programme [19]

- Royal Aeronautical Society ALTA Mentoring Platform [20]

\subsection{The role of space outreach}

\subsubsection{Objectives of space outreach}

One of the key drivers to improve diversity in the space workforce is access to the space sector for diverse audiences. There are many factors that influence the accessibility of the sector, but this often starts with awareness of opportunities in the industry among these diverse audiences. This awareness is driven by space education and outreach activities, inside and outside the formal education system. In this paper, we will focus mainly on public outreach activities outside the scope of formal education, although the two share many of the awareness objectives.

There are thousands of space outreach initiatives, programs, and campaigns around the world, all with their own specific objectives, audiences, content, and channels. If we want to understand the effectiveness of space outreach activities, we need to understand the objectives.

A paper in the Space Education and Outreach Symposium of the International Astronautical Congress
(IAC) 2017, defined the high-level objective of all education and public outreach (EPO) activities as "EPO generally focuses on "increasing overall interest, involvement in, and knowledge of scientific content and processes" [9]. Looking at space outreach more practically, roughly three main types of outreach objectives can be identified:

- Accountability - Make people aware of government tax income spending in space and the benefits of this spending to society. This applies to government space programs only, although is often also used in commercial settings for the purpose of openness.

- Inspiration - Support a healthy, diverse, and steady space industry workforce by providing realistic information about working in the sector. This is the objective that relates to the one mentioned in the IAC 2017 paper and is the most relevant for this paper too.

- Curiosity - Feed the desire to understand the world and universe around us, seeking answers to existential questions. This objective often includes entertainment content, for example for television programs, science centers, and museum exhibitions, as well as other forms of entertainment that build on people's curiosity.

\subsubsection{New outreach for new space}

With the rise of 'New Space', which is characterized by a transition from a purely government-driven space program to a market-driven space industry, where commercial companies pick up certain activities in space from government players, new objectives for space outreach are becoming commonplace. Yes, accountability, inspiration, and curiosity still play a role, but it is mixed with marketing and entertainment, with a new underlying goal of sustaining a profitable business.

\subsubsection{Space outreach for workforce development}

In the context of this paper, one specific goal of space outreach deserves special attention: the goal of maintaining a healthy, diverse, and steady space industry workforce. This objective refers to education and outreach programs with the aim to inspire children and students about education and a career in the space field. It is known that many kids want to become an astronaut, but the emphasis of these outreach campaigns should cover the full range of career options in the industry, with focus on both: the traditional, government-driven space sector, as well as new space.

The awareness created by good education and outreach will hopefully drive sufficient young people towards the thousands of jobs that need to be filled in the industry every year. An important element of these education and outreach programs are mentors and role 
models, who can help turn awareness of the sector into the realistic and achievable study and career ambitions.

\section{Survey}

The answers of 30 space communicators that practice space outreach in different countries around the world were analyzed and grouped into six topic categories.

\subsection{Target audience}

The main age range to which communicators usually target their space activities is 19 to 25 years old, while the least attended is the population under 10 years. In the graph shown in Figure 4, it can be observed that the availability of space communicators increases according to the age ranges, but presents a decrease when targeting audiences with an age above 25 years.

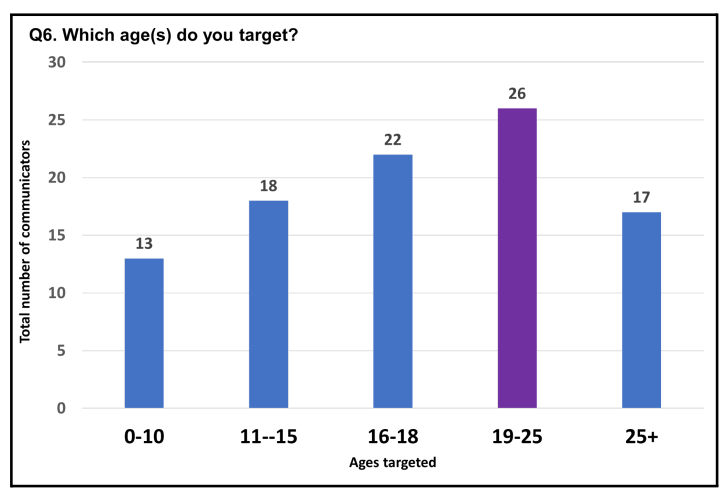

Figure 4. Q7. Which age(s) do you target?

\subsection{Presence of STEM and non-STEM careers and topics in space outreach}

When asked which kind of careers the communicators focused on when choosing topics and perspectives for their outreach activities, the majority (51.7\%) answered "Only STEM" topics, which could vary from a wide range of science and technical disciplines. Moreover, although a minority (6.9\%) focuses on sharing only non-STEM topics, such as law, communication, and business, it is relevant to report that almost half (41.4\%) of the surveyed group includes both STEM and non-STEM perspectives in their outreach activities (Figure 5).

Another question regarding the presence of non-technical careers in space outreach was: "(Q10.) Do you believe that non-technical roles are discussed enough in space outreach?" From the total number of respondents, $80 \%$ selected 'No' as an answer.

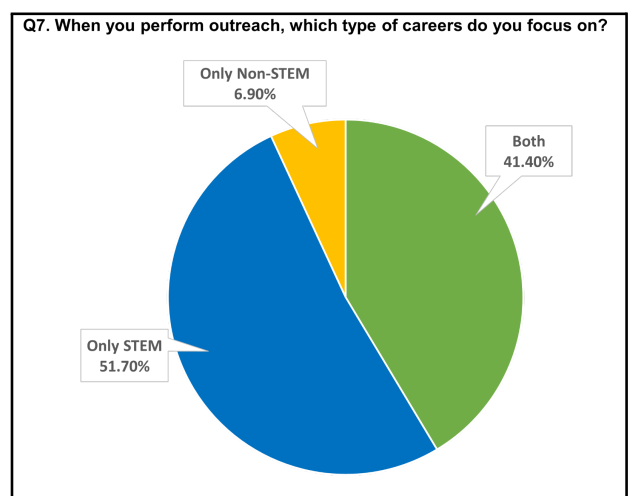

Figure 5. Q7. When you perform outreach, which type of careers do you focus on?

Furthermore, space communicators were also asked about their views regarding the visibility of multidisciplinarity in the industry; the question read as follows: "(Q12.) Do you consider that the range of careers in the space industry is presented well enough?". Even though it is an open-ended question, it was possible to categorize the answers in the following distribution:

Table 1. Q12. Answers distribution

\begin{tabular}{lll}
\hline & Responses & $\%$ \\
\hline No & 14 & $46.66 \ldots \%$ \\
Not enough & 6 & $20 \%$ \\
I don't know & 3 & $10 \%$ \\
It has been improving & 3 & $10 \%$ \\
Yes & 4 & $13.33 \ldots \%$ \\
\hline Total & 30 & $100 \%$ \\
\hline
\end{tabular}

Some respondents who answered 'no', justified their choice by saying that (a) non-technical skills and manual jobs are also needed in the industry but usually forgotten; (b) only a couple of STEM careers are currently positioned in people's minds, for instance, engineering and aerospace; (c) there is a lack of linkage between what students are learning at school and the diversity of roles in the industry.

The $20 \%$ of respondents, whose answer was 'not enough, seemed to agree with the idea that the promotion of non-STEM careers is more than just a matter of inclusivity, they considered it important to stress that these careers are a necessary component in the growth of this sector: "For the development of a global space industry, it is important to promote paths like entrepreneurship and communication".

Moreover, some of the communicators who answered 'I don't know' acknowledged that they, as well as other people, can't see if the diversity of careers is represented well enough, because of a bias-related to their professional activities: "I am so involved in the 
technical side of the space industry, that is most of what I see and experience, so I don't have a clear perspective". Others considered that such diversity depends on the experience and background of the people who volunteer to do outreach. Besides, another respondent added that it is not the objective of outreach to talk about the diversity of careers but just emphasizing the multidisciplinarity required in the industry: "Maybe the focus shouldn't be talking about STEM or non-STEM, but highlighting the transdisciplinarity of knowledge and letting the audience choose if they want to learn in-depth a career".

Finally, $23.33 \%$ of communicators considered that media outlets still have an important role in the coverage of the diversity of roles in the space industry: "Media still mostly present engineers and astronauts...but more and more we are listening to the ideas that 'aerospace isn't all' or 'there is more than just engineering".

\subsection{Impact of different space outreach methods on career development}

In order to explore the main ways in which communicators do space outreach, they were given five options to choose from: (a) Mentorships, which refer to the guidance given to an inexperienced individual for its professional growth in the space industry; (b) Direct presentations to schools or organizations; (c) Involvement or development of webinars and podcasts; (d) Designing outreach resources, which means producing teaching materials, resource packs or games that could be used at other scenarios; and (e) 'Other', were different outreach activities and methods could be described.

Figure 6 indicates that 'webinars and podcasts' are a trend, followed by a more traditional outreach approach, which is presenting directly at schools and organizations. Half of the surveyed group is also dedicated to designing outreach resources and only nine communicators shared other ideas, which are: organizing events (workshops, hackathons, camps, live astronomy events), promoting activities through membership of committees and boards at universities, not mentoring but advising enterprises, doing science journalism, and building outreach communication strategies for space projects.

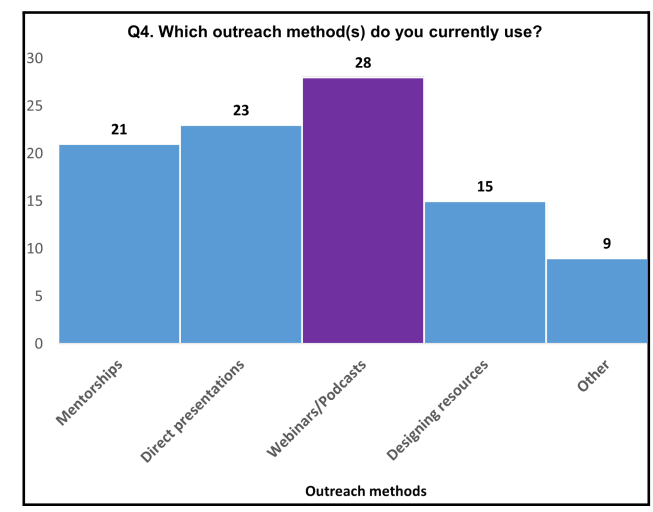

Fig.6. Q4.Which outreach method(s) do you currently use?

On the other hand, in order to explore which practices space communicators consider to have the greatest influence on motivating a student to enter the space industry, but not necessarily are practices implemented by them, the following answer options were given: (a) Public discourse and public opinion, the former understood as "the primary forum in which individual people can voice their concerns and wants and become educated about the concerns and wants of other people" [25], while the latter is defined as "the predominant attitude of a community or the aggregation of the views of individuals in society regarding a specific issue or event" [24]; (b) work experience and internships, in which students could get involved; (c) webinars and podcasts listened by students; (d) school curriculum, which refers to the availability of specialized courses offered by educational institutions; (e) mentorship programs; (f) School/university visits to space companies and agencies; and (g) 'other'. Additionally, an open-ended question was introduced for asking the surveyed communicators to justify their choice. The qualitative analysis of the responses resulted in the following observations.

\section{a) Public discourse and public opinion}

The five communicators who chose public discourse as influential justified their reasoning by saying that the collective idea that society has about the space industry could represent an advantage when it comes to promoting a career in space: "The more we talk about space in the public space, the more we can target the young generation that wouldn't be interested in the first place. With private space blooming and being more and more present in our lives, it inspires more people to join the space sector"; "Public discourse is important in creating and maintaining the perception that space industry is cool"; "Public discourse helps promote that the space industry has a reputation for needing smart, talented, motivated individuals. In that sense, parents want their kids to get involved, and the results achieved 
by the space industry are inspiring enough to draw interest and attention from a young age all throughout life."

\section{b) Work experience and internships}

As Figure 7 shows, this response was chosen as the most influential practice that could motivate a student, at a minimum, to enter the space industry. Networking, soft skills, employment opportunities, and real-life experiences were listed as the most attractive and influential attributes of internships. However, a couple of respondents emphasized that although they consider that work experience is determinant for building a career in space, not all countries have these opportunities as realistic options for their youth. For instance, one answer stated that "internships in Latin America or abroad are limited to students who are already in higher education levels, mostly to the ones that have completed a graduate program, so this is not a viable option for everyone".

\section{c) Webinars and podcasts}

Digital content, such as webinars, podcasts, live streamings, and masterclasses, just to mention a few, were pointed as "resources with the potential to have a great influence on students", because of their accessibility and proximity to a diverse range of voices: from students who share their passion for science and space to experts that are currently working in the space industry. "I think that in webinars, getting to talk with people working in the field you want to get into it becomes an invaluable experience, because they have insights to share that can help you realize how many paths there are to get to where you want to be", answered one of the communicators.

Still, some respondents recognized that digital resources "are limited to reach an audience with certain privileges such as internet access and a smartphone", while others added that "digital content can become abundant, overwhelming and unreliable". This answer option was the least voted, as shown in Figure 7.

\section{d) School curriculum}

Educational quality is the option that resulted in the middle of the distribution of the answers (Figure 7). The analysis revealed two common responses: First, some respondents shared that they have identified that not all schools include technical, vocational, and/or business knowledge in their curriculum and, instead, opt for a more traditional learning path: "Courses are exclusively focused on academic knowledge and the route through University...schools should focus on covering those topics alongside the academic side to give a fair opportunity to all students to find the right path for them".

The second group of responses focused on the importance of making science a close topic for young people from an early age: "I believe that the educational foundation of those who enter the aerospace industry is critical and can be the deciding factor of a student's success. This starts in grade school and extends into university. If students are exposed to STEM at an early age and encouraged by their teachers/parental figures to pursue these areas, they will be much more inclined to go into the field."

\section{e) Mentorship programs}

This resource was chosen as the second with the greatest power of influence over students and their possible careers in the space sector (Figure 7). As a participant in the program, a student is paired with a mentor who is experienced in a field and who will guide her/him individually through a project or in the establishment of professional goals.

Overall, respondents agreed that mentoring is an enlightening activity that allows students to confidently share their dreams and doubts, while they build a dialog with someone who is willing to show them how to navigate the industry challenges. Here are some highlights: "I have realized that a mentor possesses a significant influence due to the ability to do human storytelling"; "Mentoring is the most important because you can't navigate anything else without someone there showing you how things work along the way. It's key to have someone invested in your presence within that field."

\section{f) School visits}

Visiting space companies or agencies was not considered to have a significant influence on students and their careers. Nevertheless, an important contribution from the responses is pointing out that practical rather than only theoretical experiences could really impact the way students perceive science: "I think things that form part of school life, i.e. a trip, or a visit from a company or ambassador to give a careers talk or something similar, don't feel quite like a 'boring school lesson', and so students may be a bit more engaged - it simply raises awareness and opens young minds to more possibilities and help them believe that the space industry is not out of reach to a normal child."

\section{g) Other}

Additional ideas were provided by three respondents. The first one consists of getting students closer to the traditional houses of science and knowledge: "Neither the school nor online content. I think that what most impacts young people is getting in 
personal contact and listening to those who have had experiences in the industry. Attending planetariums, science museums or even going to astronomical observations or camps are great opportunities where they can interact with experts in the field".

The second suggestion was 'student organizations and clubs, which are spaces where young people can meet others with similar interests and provide feedback to each other: "I have tried getting involved in student organizations and clubs at universities to reach folks who are also thinking about getting jobs and doing things to prepare themselves to enter the workforce."

And finally, another respondent identified 'hackathons' as great opportunities for space organizations to connect with students: "I believe strongly in their benefits: a) educate people about the challenges and opportunities space agencies are facing; b) allow to gain experience in important skills and team building, including with virtual communities; c) help students understand that they can contribute to a team even without "space skills"; and d) make students part of an international community of like-minded people who are passionate about space, exploring the universe, and solving problems on Earth."

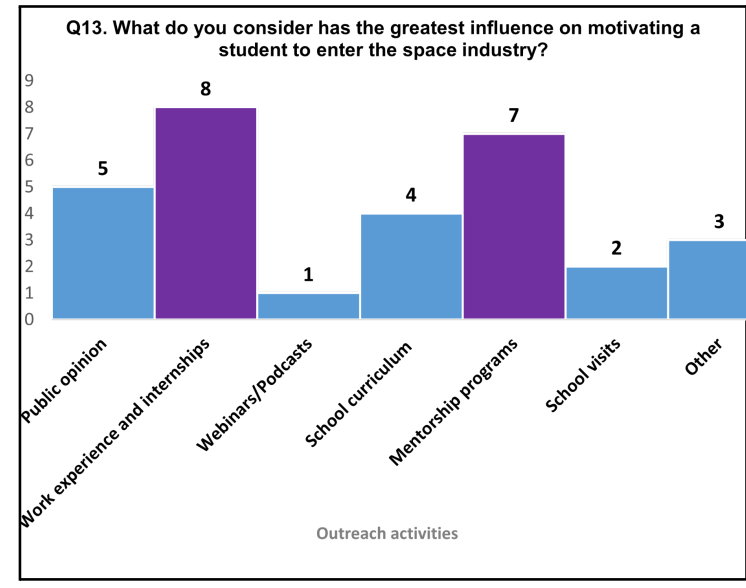

Figure 7. Q13. What do you consider has the greatest influence on motivating a student to enter the space industry?

\subsection{Space outreach around the world}

The space communicators who participated in this survey currently do space outreach in Asia (3\%), America (40\%), European Union (EU) countries (10\%), other non-EU countries in Europe (40\%), and globally (7\%).

Questions number 1 and 8 from the survey (Appendix B) were merged for analyzing the geographical distribution of how strong communicators believe that space outreach is effective for encouraging students to pursue a career in space. On a scale from 1 to 10 , being 1 'less strongly' and 10 'more strongly', the distribution is shown in Figure 8.

As a result, it was found that communicators doing outreach in countries with a strong space program or agency, such as the US, UK, Canada, Spain, and India, tended to rate the effectiveness of outreach over students' motivations on a scale of 7.5 to 8 . In contrast, communicators performing in countries with little or no space activity, such as Mexico, rated the impact of outreach over career decisions with an average of 2.5.

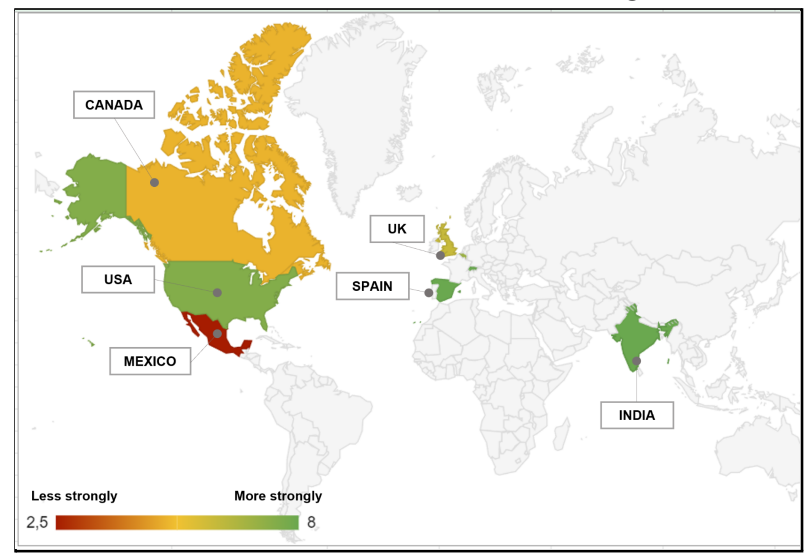

Figure 8. Geographical distribution of the perception about outreach effectiveness, on a scale from 1 to 10.

\subsection{Diversity and inclusivity}

"Diversity and inclusivity are important when working in an industry that's targeted at human exploration and well-being", answered one of the surveyed communicators when asked about why and how outreach should be targeted to improve inclusivity and diversity.

Responses varied as follows:

a) Showcasing people from un/underrepresented groups and from diverse professional backgrounds, or even having them doing outreach, could help students relate easily with a role in the industry.

b) Start including other topics, such as soft skills building, and other target audiences, such as neurodiverse people, on the outreach agenda.

c) Expand the range of outreach venues: from schools and museums to parks, libraries, and other local places of reunion for communities.

d) Improve space outreach in general and then focus on target audiences.

e) Contribute to maximizing the visibility of outreach initiatives that are already inclusive.

\subsection{General perception of the space industry}

The answers to the question (Q15) "Why do you believe that there is a perception that the space industry is difficult to enter, and how can we combat this?" were 
grouped into six categories, based on the main idea of the response:

\section{a) People are still not aware of the 'new space'.}

Five respondents $(16.6 \%)$ suggested that society, in general, is still not aware of the recent changes in the space industry (as pointed out in section 3.4.2), regarding stakeholders, commercial context, social benefits, and technology applications: "I think new space hasn't yet become 'mainstream' enough for people to see that there are different parts of space, (...) the more we can showcase the benefits of this era, (...) the more people will see that space runs across every sector and the opportunities to be involved are limited only by imagination"; "People are still afraid of the things that they don't know (...) we have to demystify the industry and be more inclusive."

b) People perceive that the space industry is exclusive or limited to certain countries and socio-economic levels.

In contrast to the paragraph above, four respondents $(13.3 \%)$ pointed out that difficult access to space industry is not just a matter of perception, but a reality: "The core of space activities is in a couple of leader countries"; "People who have studied in space-dedicated programs can enter the space industry more easily because the school is known in the industry and because of the network; "To combat this perception, having more space-dedicated career fairs would help."

\section{c) People still believe that STEM careers and technical skills are everything in the space industry.}

Four respondents (13.3\%) noted the importance of communicating that soft and non-technical skills, as well as multidisciplinarity, are needed in the space industry: "We need people currently working in the sector tell students about the personal qualities and skills they value - not always focus on STEM-based qualities and skills"; "Outreach has been targeted to fields that require quite a bit of math. A lot of people feel that they're not good at math and there's a mental block. They don't realize that any skills can be useful to this field."

\section{d) People consider that the space industry is too difficult and challenging.}

Five respondents (16.6\%) suggested that outreach has an important role in guiding, discussing, and showcasing career paths in space, as well as in identifying prospects among the public: "Great challenges should be answered by those with the drive to do so, and outreach is a fantastic way to ensure you are finding those who want to participate while combating the idea that it's impossibly difficult"; "It's a combo of understanding the opportunities and how to make the most of them"; "I think the perception that the industry is difficult to enter is somewhat misplaced and in reality, it is simply a technically challenging field. We can work to combat this through outreach by encouraging students to solidify their skills which will then allow them to succeed in the field."

\section{e) People have such perception because of the present role models promoted in society:}

The rest of the respondents (twelve in total - 40\%) indicated that the perception about the space industry being difficult is principally related to how society and media have showcased space careers.

First, they considered it important to communicate the human and ordinary nature of the space industry; a couple of answer examples are: "I think this exciting and futuristic industry seems out-of-reach until it is brought closer to them by people working in the industry; there is a perception that you need to be a genius to achieve the incredible feats the industry has done, that it is not possible for someone who feels 'ordinary' to achieve, so showing that isn't the case - that people in the space industry are just like everyone else, are ordinary too, might help to encourage young people to not only look to the stars, but aim for them too"; "We need young people to be making directional choices since primary school levels, and not giving them the idea that they need to aim for a $\mathrm{PhD}$ before they can enter the space industry."

Secondly, respondents spotlighted the role of the media in the diverse and inclusive coverage of space actors: "Movies and media depict it as a very competitive industry, which only the best of the best can get into"; "We oversell the technical complexity and how smart we are and the press make this worse because they exaggerate the high technical knowledge"; "Certainly, there are currently non-STEM people in the teams behind the technical glamorous careers, like astronauts and engineers, who get a lot of attention"; "Technical careers take up most of the publicity".

Finally, the responses also suggested that when selecting a story to tell, it would be impactful to share non-traditional career paths: "You can overcome this perception by giving young people to engage with and hear the career journeys of people who followed alternative and unusual journeys into the space sector"; "Space is seen as an elite field (...) We should show that you don't need to be at the top of your university to succeed in this field: you should take the path less traveled that fits what you enjoy most and not the path that seems the most technical, best quality, etc"; "Because many people that work in the industry are 
perceived as having a high level of education and a traditional academic path (...) Providing visibility of folks from different backgrounds/paths will be key in helping to combat this perception."

Although one of the respondents recommended for achieving this objective to focus on other stakeholders who have influence over young people: "The biggest issue is convincing parents, teachers and, particularly, schools careers advisors that this is the case as my feeling is all those groups default to the view that University is the only route into the industry".

\section{Discussion and conclusions}

\subsection{Findings from the literature review}

The literature review revealed that the space industry is undergoing rapid growth, with more people worldwide working in the sector, more countries becoming part of the space-faring nations, and a shift from government-only to a mix of government and commercial jobs being filled in the sector. At the same time, there is still a geographical bias in the industry, with the large majority of jobs being in North America, Europe, Russia, and a small number of countries in Asia. There is hardly a significant number of jobs in Africa, Latin America, and the majority of Asia.

A review also finds an imbalance in the representation of certain societal groups in the industry. Most attention at the moment is going to the gender imbalance in the industry, which is largely male-oriented. There are also imbalances in minority groups in society, including ethnic minorities and disabled people, although there is not much research available in those areas. It also deserves to mention that most initiatives to increase the inclusion of women and minorities are happening in North America and Europe, although initiatives exist with international NGOs to improve imbalances in other regions too.

An analysis of the concepts of role models and mentors clearly proves the relevance of these role models for inclusion and a diverse workforce. The space industry seems aware of this relevance, looking at the many initiatives to highlight new role models and start new mentoring programs specifically aiming at inclusion.

Research also shows that all these efforts start with education and outreach, to create awareness of the opportunities of space for education and careers, using the correct role models to attract as wide and diverse an audience as possible.

In 2021 we saw a number of high profile and widely promoted commercial human space flight missions. The example set by these missions, even though some incorporate a diversity and inspiration objective, is working largely counterproductive. Although no hard scientific evidence for this yet exists, these missions are initiated and largely executed by rich white men with a US or other western passport and a few selected passengers. The message that these missions help make space more accessible to anyone may be true in the far future, but these missions definitely are not perceived as such by people from diverse backgrounds at the moment.

\section{$\underline{5.2 \text { Findings from the survey }}$}

\subsubsection{Outreach methods}

Our survey among outreach communicators showed that most programs under the control of the people surveyed aim at students (19-25-year-olds), with less focus on younger ages, although all are covered.

Most of the people surveyed have a primary focus on STEM, although many focus on both STEM and non-STEM subjects within space and science, there seems to be a strong focus on technical aspects of space.

Despite the hypotheses from the literature review that the new private human space missions do not inspire the whole world. people surveyed indicate that the massive media attention does provide awareness and inspiration among their audiences.

The most impactful outreach methods are found to be internships and mentorship programs. Internships have a high impact, but are reported as not very widely available, and therefore not a realistic option for the majority of students around the world. Mentorship programs are found to have a very high impact, which corresponds with the literature findings that the personal relationship of mentors and mentees helps strengthen students in their belief that they can achieve the same results.

Relevant during the Covid-19 pandemic, and selected as one of the most widely used outreach tools, webinars and podcasts can have a great influence on students, as they bring role models in very close contact with students. They do require access to the necessary digital tools, which are not available for all audiences, especially the underprivileged. Additionally, digital content is not always considered reliable.

An important outreach channel is formal education. The survey indicates that not all schools include STEM and space topics in their very full formal academic curricula, as these have to cover a wide variety of other topics too. Nevertheless, those respondents active in school programs recognize the importance of exposing school children to STEM topics as early as possible.

School trips and visits of STEM organization representatives to schools are seen to have limited influence on students aspiring to a STEM career, even 
though they do provide students a realistic picture of what the space sector really looks like in practice.

Slightly in contrast with the previous, respondents do indicate the influence of practical activities, school STEM clubs, and things like 'hackathons'. Perhaps this is related to hands-on learning as a more effective way of exciting students for STEM than just visits or demonstrations.

\subsubsection{Geographical differences}

There is a very interesting geographical difference between respondents' perception of the outreach effectiveness, where countries with an established space sector perceive this effectiveness as higher than those in countries with a much less established space industry. This deserves further research.

\subsubsection{Diversity and inclusion}

Some very powerful conclusions can be drawn from this section of the survey. Understanding the diversity of the audiences seems to be an important factor to successful outreach, which can be further aided by having similarly diverse role models, a de-emphasis of the STEM element of the industry (the industry is more than astronauts, scientists, and engineers), a variety of channels to ensure inclusion of un/underrepresented audiences and a maximization of the visibility of outreach programs that are already inclusive.

\subsubsection{The perception of a 'closed'space industry}

When asking respondents why they may believe that there is a perception that the space industry is difficult to enter and how we can combat this, the answers covered the following six reasons:

1. People are still not aware of 'new space'

2. People perceive that the space industry is exclusive or limited to certain countries and socio-economic levels.

3. People still perceive the space industry as STEM only (think that it IS rocket science)

4. People consider that the space industry is too difficult and challenging.

5. People have such perception because of the present role models promoted in society

\section{Recommendations}

\subsection{Recommendations for space outreach practitioners}

An important step on the road to a diverse and inclusive outreach is understanding the diverse audiences: specific outreach strategies should be created according to the characteristics of a target audience and not vice versa; this means that space outreach should be designed for a defined audience and not expect a public to fit general outreach..
Some insights regarding the way space outreach is currently performed are: remember to do online and offline outreach activities in order to reach audiences with different social contexts, as well as attending early-age kids (from 0 to 11 ) and adults (from 25 years on), who still have opportunities in the space sector. Furthermore, spotlighting the international opportunities that are currently available for participating in the space industry, whether at an amateur or professional level, would contribute to the integration of various regions of the world into the space sector.

As described in sections 3.1.2, 4, and 5.2.2, not all countries in the world are equally active in the space sector, due to social, political, and economical factors. How can these populations be motivated to develop a career in the space sector, which in turn could even lead to the development of their country's space sector? Who could be an effective role model, if there is little or no space activity? One proposal is to identify and showcase success stories of local people who have developed a career in the space sector abroad. These cases can empathise and inspire the population from their home countries. This idea corresponds to the category of 'inspirational outreach' (section 3.4.1).

Finally, it is important to have in mind that space outreach can have an important influence on public opinion. Space outreach influences parents, teachers, and other social actors who, at the end of the day, are closer to student and young people.

\subsection{Recommendations for further research}

The insights around the relationship between media coverage and the visibility of diversity in the space sector could be deepened with a study that addresses the theories of agenda-setting and framing, which aim to analyze how editorial and content decisions influence the way audiences are informed and, what is more, the perception they will have on a topic (See Maxwell McCombs and Donald L. Shaw).

This paper revealed a very interesting geographical difference between respondents' perception of the outreach effectiveness, where countries with an established space sector perceive this effectiveness as higher than those in countries with a much less established space industry. This deserves further research, including the social, political and economic aspects that permit, enhance or limit space outreach. 


\section{References}

[1] Inspiration4, The Mission, February 2021, https://inspiration4.com/mission $\quad$ (accessed 29 September 2021)

[2] OECD (2019), The Space Economy in Figures: How Space Contributes to the Global Economy, OECD Publishing, Paris, https://doi.org/10.1787/c5996201-en.

[3] Oxford English Dictionary. (2021) reference, Oxford University. [Online] [Accessed on 29 September 2021] http://www.oed.com/view/Entry/56064

[4] A. van Dam, Royal Society Open Science, July 2019, Volume 6, Issue 7, "Diversity and its decomposition into variety, balance and disparity" https://doi.org/10.1098/rsos.190452

[5] McKinsey and Company, "Diversity wins: How inclusion matters", May 2020, https://www.mckinsey.com/ /media/mckinsey/featured $\% 20$ insights/diversitv $\% 20$ and $\% 20$ inclusion/diversitv $\% 2$ 0wins $\% 20$ how $\% 20$ inclusion $\% 20$ matters/diversity-winshow-inclusion-matters-vf.pdf

[6] Spacepolicyonline.com, December 2020, "International Space Activities", https://spacepolicyonline.com/topics/international-space -activities/ (accessed 28 September 2021)

[7] Wikipedia, Spaceflight, last edited 23 September 2021,https://en.wikipedia.org/wiki/Spaceflight

(accessed 28 September 2021)

[8] International Astronautical Federation, "IAF 3G International Patform for Diversity and Equality in Astronautics (IDEA) - 3G Geography, Generation, Gender",

https://www.iafastro.org/activities/iaf-3g-international-p latform/ (accessed 28 September 2021)

[9] Kingsley, Oliver and Van Kranendonk, September 2017, "Space Science Outreach - Are we decreasing public understanding", International Astronautical Congress paper for IAC2017, IAC-17.E1.6.x40259

[10] Aish, Nir; Asare, Philip; and Miskioglu, Elif Eda, 2018, "People Like Me: Providing relatable and realistic role models for underrepresented minorities in STEM to increase their motivation and likelihood of success". Faculty Conference Papers and Presentations. 51. https://digitalcommons.bucknell.edu/fac conf/51

[11] Van Camp, A., Gilbert, P., \& O'Brien, L.T. (2019). Testing the effects of a role model intervention on women's STEM outcomes. Social Psychology of Education, 22 , 649-671.

https://doi.org/10.1007/s11218-019-09498-2

[12] Shapiro, E.C., Haseltine, F. P. and Rowe, M. P. (1978), Moving up: Role models, mentors, and the "patron system. Sloan Management Review; 19, 51-58.
[13] Singh, V, Vinnicombe, S, James, K. (2006), "Constructing a professional identity: how young female managers use role models", Women in Management Review

[14] Gibson, D.E. (2004) "Role models in career development: New directions for theory and research", Journal of Vocational Behavior, 65, 134-156.

[15] Lockwood, P. and Kunda, Z. (1997), "Superstars and me: Predicting the impact of role models on the self", Journal of Personality and Social Psychology, 73 (1) 91-103.

[16] Gorman, Alice, June 2020, “Almost 90\% of astronauts have been men. But the future of space may be female", The Conversation, https://theconversation.com/almost-90-of-astronauts-ha ve-been-men-but-the-future-of-space-may-be-female-12 $\underline{5644}$ (accessed 27 September 2021)

[17] UNOOSA Space4Women Mentorship Program, 2021,

https://space4women.unoosa.org/mentorship-program (accessed 29 September 2021)

[18] Space Generation Advisory Council (SGAC) Mentoring Program, 2021, https://spacegeneration.org/mentoring (accessed 29 September 2021)

[19] IAF Launchpad Mentorship Programme, 2021, https://www.iafastro.org/activities/iaf-launchpad-mentor ship-programme.html (accessed 29 September 2021)

[20] Royal Aeronautical Society ALTA Mentoring Platform, 2021, https://www.aerosociety.com/get-involved/women-in-av iation-aerospace-committee/alta-mentoring-platform/ (accessed 29 September 2021)

[21] Virgin Galactic's SpaceShip Two Unity 22 launch with Richard Branson, Space.com, 2021, https://www.space.com/virgin-galactic-richard-bransonunity-22-launch-explained, (accessed 29.09.2021)

[22] Blue Origin launches New Shepard to test moon landing tech and more in suborbital flight, Space.com, 2021, https://www.space.com/blue-origin-new-shepard-ns-17suborbital-launch-success, (accessed 29.09.2021)

[23] Blue Origin announces next customers to fly on New Shepard's upcoming human flight on October 12, Space.com, 2021, https://www.blueorigin.com/news/next-human-flight-on -october-12, (accessed 29.09.2021)

[24] Merriam-Webster Dictionary, public opinion, https://www.merriam-webster.com/dictionary/public $\% 2$ 0opinion

[25] Sellers M.N.S, 2003, "Chapter 8: Ideals of Public Discourse", in "Republican Legal Theory", Palgrave Macmillan, London, https://doi.org/10.1057/9780230513402 8 


\section{Appendix A (Survey: Space Outreach around the world)}

1. Which country do you perform outreach in?

2. What is your age?

3. What gender do you identify as?

4. Which outreach method(s) do you currently use? Please select one or more options.
a. Mentorships
b. Direct presentations to organizations/schools.
c. Participating in webinars/podcasts
d. Designing resources (games/resource packs/teaching plans)
e. Other

5. If you answered 'other' please outline below.

6. Which age(s) do you target?
a. $0-10$
b. 11-15
c. $16-18$
d. $19-25$
e. $25+$

7. When you perform outreach, which type of careers do you focus on?
a. STEM
b. Non-STEM
c. Both

8. From 1 to 10 , being 1 'less strongly' and 10 'more strongly': How strongly do you believe that current outreach methods effectively encourage students to pursue a career in the industry?

9. Do you discuss pathways into the space industry (degree options/internship suggestions/networking advice)?
a. Yes
b. No

10. Do you believe that non-technical roles are discussed enough in space outreach?
a. Yes
b. No

11. Do you believe that outreach should be targeted to improve inclusivity and diversity? If so how?

12. Is the range of careers in the space industry presented well enough?

13. Which of the following do you consider has the greatest influence on motivating a student to enter the space industry?
a. Public opinion
b. Work experience and internships
c. Webinars/podcasts
d. School curriculum
e. Mentorship programs
f. School/university visit
g. Other

14. Please state the method you chose and why you believe it is most effective.

15. Why do you believe that there is a perception that the space industry is difficult to enter, and how can we combat this? If you disagree, please explain why.

16. What caused you to enter the space industry? 